\title{
A Utilização do Laudo Pericial Elaborado pelo Perito Contador: Um Estudo Descritivo nas Varas Cíveis Estaduais da Cidade de Maceió-Alagoas
}

\author{
The Use of the Report Prepared by the Expert Counter: A Descriptive Study on \\ the State Civil Jurisdictions City of Maceió, Alagoas
}

Luiz Carlos Marques dos Anjos

Mestre em Contabilidade (UFPE)

Professor da Universidade Federal de Alagoas (UFAL)

\author{
Rommel de Santana Freire \\ Mestre em Administração (UFPB) \\ Professor Assistente da Universidade Federal da \\ Paraíba (UFPB)
}

Aline Rúbia Ferraz de Freitas

\author{
Jefferson David Araújo Sales \\ Doutorando em Administração (UFPE) \\ Mestre em Administração (UFPB) \\ Professor Assistente da Universidade Federal \\ de Sergipe (UFS) \\ Daniel José Cardoso da Silva \\ Mestre em Contabilidade pela UFPE \\ Professor Assistente de Universidade Federal \\ de Alagoas (UFAL)
}

\section{Resumo}

Este trabalho é resultado de um estudo teórico-empírico na área de Perícia Contábil, que teve como objetivo analisar a utilização dos laudos periciais contábeis em função de possuírem linguagem simples, clara, concisa e objetiva, na visão dos magistrados das varas cíveis estaduais da cidade de Maceió - Alagoas. Sua execução teve como ponto de partida a revisão da literatura e documentos legais que fundamentaram um estudo empírico em treze varas cíveis da esfera estadual, localizadas na Cidade de Maceió/AL, com a preocupação de orientar um trabalho pericial de qualidade desde a nomeação do perito até a apresentação do Laudo Pericial, além de destacar o perfil profissional exigido para aqueles que atuam nessa área. Para o propósito do presente estudo, visando uma maior confiabilidade, a amostra foi formada por Juízes que fossem titulares de Varas Cíveis. A entrevista foi feita por meio de questionário estruturado, baseando-se na literatura que norteia a pesquisa em tela, além de observações dos próprios pesquisadores. O tratamento dos dados deu-se através da estatística descritiva. O estudo se limitou a uma única esfera judiciária, a Justiça Estadual de Alagoas Comarca de Maceió, sendo assim, um estudo de um único caso. Dessa forma, todas as conclusões encontradas são exclusivas da entidade estudada, não podendo ser generalizadas para outras instâncias. A pesquisa mostra que os juízes têm uma percepção satisfatória dos laudos periciais contábeis elaborados pelos perito-contadores por eles nomeados. Entretanto foram identificados pontos controversos que têm influenciado ou no tempo para deslinde do litígio, ou na decisão judicial.

Palavras-Chave: Perícia Contábil. Responsabilidade do Perito-Contador. Utilização do Laudo Pericial Contábil.

\footnotetext{
Abstract

This work is the result of a theoretical and empirical research in the area of Forensic Accounting, which aimed to analyze the use of forensic accounting reports in terms of having simple, clear, concise and objective language, in view of the judges of the circuit courts of the city of Maceió Alagoas. Its execution took as starting point a review of the literature and legal documents justifying an empirical study in thirteen circuit courts of the state level, located in the city of Maceió / AL, with a view
} 
to guiding the good quality work of the expert since the his appointment to the presentation of the technical report, and highlight the professional profile required for those working in this area. For the purpose of this study the sample was composed of judges who were holders of Courts. The interview was done through a structured questionnaire, based on the literature that guides the search screen, as well as observations of the researchers themselves. The processing of data was by descriptive statistics. The study was limited to a single judiciary, the State Court of Alagoas - Maceió County, so a study of a single case. Thus, all conclusions reached are solely those of the organization studied and can not be generalized to other cases. Research shows that judges have a satisfactory understanding of forensic accounting reports prepared by expert accountants nominated by them. However controversial points have been identified that have influenced or time to unravel the case, or court order.

Keywords: Forensic Accounting. Forensic Accountant Responsibility. Forensic Accounting Reports Utilization.

\section{INTRODUÇÃO}

No último século a história brasileira foi repleta de eventos desestabilizantes tanto nos âmbitos político, econômico e financeiro. Investimentos regionalizados, inflação galopante, altos índices de corrupção, coronelismo, trocas de regimes políticos e de moedas, etc. Estes são exemplos da enorme dinâmica que a sociedade brasileira enfrentou nesse período. Obviamente que fatos como esses acabam deixando seqüelas gravíssimas na sociedade, e uma das principais é a grande acumulação de capital por uma pequena parcela da comunidade refletindo em uma distribuição de renda desigual.

Mudanças constantes na legislação tributária, previdenciária e trabalhista também ocasionaram duros impactos aos cidadãos. Com isso, a Justiça acaba sendo o melhor, se não o único, meio para reivindicar direitos suprimidos, sejam do indivíduo, de uma empresa ou de qualquer instituição, quer seja de direito público ou privado.

No âmbito judicial, como principal agente da justiça na solução dos litígios, o juiz pode utilizar vários instrumentos probantes para que possa proferir uma livre decisão, porém fundamentando-a de acordo com as normas legais.

A legislação brasileira elenca uma série de provas que poderão ser utilizadas na busca pelos direitos no âmbito judicial. Tais provas estão especificadas no Código de Processo Civil (CPC), e são elas: depoimento pessoal; confissão; exibição de documento ou coisa; prova documental; prova testemunhal; prova pericial e inspeção judicial. (CPC arts. 332 - 443)

Alberto (2002, p.19) afirma que "Perícia é um instrumento especial de constatação, prova ou demonstração, científica ou técnica, da veracidade de situações, coisas ou fatos”.

Quando o juiz necessitar de informações técnicas e científicas para fundamentar sua decisão em uma determinada área, ele poderá recorrer ao auxílio de um ou mais peritos. Estes são profissionais dotados do conhecimento necessário para colaborar com a solução da causa através de um laudo técnico.

A prova pericial contábil é um direito garantido constitucionalmente, que as pessoas naturais e jurídicas utilizam para comprovar suas teses, se defender e até mesmo exigir os direitos que considerem terem sido feridos (ORNELAS, 2000)

Padoveze (2004), afirma que a Contabilidade é considerada a ciência da evidenciação e do controle, e que esta vem sendo cada vez mais utilizada pelos magistrados como meio probante na solução de litígios.

Dessa forma, o resultado de uma perícia contábil judicial tem imenso valor para a sociedade como um todo, tendo em vista que pode fundamentar uma ou várias decisões e, conseqüentemente, até criar uma jurisprudência. Há de se observar se os magistrados estão conseguindo compreender o laudo pericial contábil e utilizá-lo para embasar sua decisão. 
Deve-se ressalvar que a qualidade do trabalho entregue pelo perito sempre estará ligada diretamente à sua capacidade técnica e ao material que dispõe para trabalhar. O reflexo dessa qualidade tem conexão direta com o auxílio para a justa decisão do magistrado. A avaliação dessa capacidade é feita pelos juízes no momento da nomeação do perito.

Diante do exposto levantamos a seguinte questão: a utilização dos laudos periciais contábeis está contribuindo para a tomada de decisão dos magistrados das varas cíveis estaduais da comarca de Maceió?

Para responder à questão proposta, será imprescindível entrevistar os juízes para poder analisar a utilização dos laudos periciais contábeis em função de possuírem linguagem simples, clara, concisa e objetiva, na visão dos magistrados das varas cíveis estaduais da cidade de Maceió - Alagoas.

\section{REVISÃO DA LITERATURA}

\section{Breve Histórico da Perícia Contábil}

Observam-se indícios de perícia desde o inicio da civilização, entre os homens primitivos, quando o líder desempenhava todos os papeis: de juiz, de legislador e executor. Existem registros, na Índia, do surgimento do árbitro eleito pelas partes, que desempenhava o papel de perito e juiz ao mesmo tempo. Também se encontram vestígios de perícia nos antigos registros da Grécia e do Egito, com o surgimento das instituições jurídicas, área em que já naquela época, se recorria aos conhecimentos de pessoas especializadas. (ANJOS, LIMA e MARTINS; 2007)

Porém, a figura do perito, ainda que associada a árbitro ficou definida no Direito Romano primitivo, no qual o laudo do perito constituía a própria sentença, somente sendo desvinculada da figura do árbitro depois da Idade Média, com o desenvolvimento jurídico ocidental (OLIVEIRA; 2005). A partir do século XVII foi criada, definitivamente, a figura do perito como um auxiliar da justiça, criando desde então a possibilidade de especialidade no trabalho judicial (FONSECA; 2000). Lopes de Sá (2002, p.13) afirma que:

No Tempo do Brasil colônia, relevante já era a função contábil e das perícias, conforme claramente evidenciado no Relatório de 19 de junho de 1779 do Vice-rei Marquês do Lavradio ao seu sucessor Luís de Vasconcelos e Sousa (Arquivo Nacional do Rio de Janeiro).

Ainda de acordo com Fonseca apud Alberto (2000), vemos que "no Brasil a perícia judicial foi introduzida pelo Código de Processo Civil de 1939, em seus artigos 208 e 234, que regulam a perícia, nomeação do perito pelo juiz e indicação pelas partes".

No Brasil, a Perícia Contábil, a despeito do Código de Processo Civil (CPC) de 1939 haver estabelecido vagas regras sobre perícia, foi institucionalizada somente com o advento do Decreto-lei no 9.295 de 27 de maio de 1946, que criou o Conselho Federal de Contabilidade e definiu as atribuições do Contador. Com o segundo Código de Processo Civil - Lei $n^{\circ} 5.869 / 73$, e as modificações pelas Leis $n^{\circ} 5.925 / 73,7.270 / 84$ e 8.455/92, as perícias judiciais foram premiadas com uma legislação ampla, clara e aplicável.

O Conselho Federal de Contabilidade, órgão regulador da profissão contábil no Brasil, em 1992, editou as resoluções $n^{0} 731$ e 733, que aprovaram respectivamente as Normas Brasileiras de Contabilidade: Normas Profissionais 2 e Normas Técnicas 13, disciplinando os procedimentos do perito e a execução do trabalho pericial contábil. Em 1999 tais resoluções foram revistas e atualizadas, através das resoluções de números 857 e 858 de 21 de outubro de 1999, corpo regulador da perícia contábil no Brasil. 
A qualidade da prova pericial, pela sua própria essência, quando peticionada em juízo, independentemente da sua natureza, vai ser fator determinante para decisão da parte vencedora, pois será a principal ferramenta fundamentadora da decisão judicial (HOOG, PETRENCO; 2002).

\section{Conceito e Objetivos da Perícia Contábil}

A perícia contábil é uma especialidade da prova pericial e por perícia entende-se como sendo o meio de prova destinado a esclarecer o juiz, sobre circunstâncias relativas aos fatos conflituosos, que envolvem conhecimentos técnicos e científicos. Cabral (2000, p. 50) conceitua-a da seguinte forma:

A expressão perícia advém do latim peritia, que em seu sentido próprio significa conhecimento, habilidade, saber: perícia é uma diligência realizada ou executada por peritos, a fim de esclarecer ou evidenciar certos fatos objeto do litígio judicial ou de interesse extrajudicial.

Outros autores, como é o caso de Alberto (1996) abordam a discussão através do objeto da ciência contábil, como segue:

Definido que o objeto da Ciência Contábil é o patrimônio, já podemos, logicamente, inferir que a perícia será de natureza contábil sempre que recair sobre elementos objetivos, constitutivos, prospectivos ou externos, do patrimônio de quaisquer entidades, sejam elas físicas ou jurídicas, formalizadas ou não, estatais ou privadas.

Já Lopes de Sá (2002) cita perícia contábil como sendo a verificação de fatos ligados ao patrimônio individualizado visando oferecer opinião, mediante questão proposta. Portanto, entendemos ser perícia contábil a forma de se demonstrar, por meio de laudo pericial, a verdade de fatos ocorridos no patrimônio de pessoas físicas ou jurídicas, contestados por interessados, examinados por um contador, e a qual servirá como meio de prova em que se baseia o juiz para resolução de determinado processo.

Os objetivos da perícia contábil são discutidos por Anjos, Lima e Martins (2007) através do quadro a seguir:

\begin{tabular}{|l|l|}
\hline Objetividade & não se desviar da matéria que motivou a questão \\
\hline Precisão & $\begin{array}{l}\text { oferecer respostas pertinentes e adequadas às questões formuladas } \\
\text { ou finalidades propostas }\end{array}$ \\
\hline Clareza & $\begin{array}{l}\text { usar em sua opinião de uma linguagem acessível a quem vai } \\
\text { utilizar-se de seu trabalho, embora possa conservar a terminologia } \\
\text { tecnológica e cientifica em seus relatos }\end{array}$ \\
\hline Fidelidade & $\begin{array}{l}\text { não se deixar influenciar por terceiros, nem por informes que não } \\
\text { tenham materialidade e consistência competentes }\end{array}$ \\
\hline Concisão & $\begin{array}{l}\text { evitar o prolixo e emitir uma opinião que possa de maneira fácil } \\
\text { facilitar as decisões; }\end{array}$ \\
\hline Confiabilidade & $\begin{array}{l}\text { estar à perícia apoiada em elementos inequívocos e válidos legal e } \\
\text { tecnologicamente; }\end{array}$ \\
\hline Plena satisfação da finalidade & ser coerente com os motivos que o ensejaram \\
\hline
\end{tabular}

Quadro 1 - Objetivos Específicos da Perícia Contábil

FONTE: Anjos, Lima e Martins (2007)

\section{Tipos de Perícia}

A perícia, por ser um instrumento especial, tem espécies distintas, definidas segundo os ambientes de sua atuação. Segundo Alberto (1996), são estes "ambientes que delinearão 
suas características intrínsecas e as determinantes tecnológicas (o modus faciendi) para o perfeito atendimento do objeto e dos objetivos para os quais deve se voltar". As espécies de perícia, que ocorrerão em seus respectivos ambientes, são: a judicial, a extrajudicial, semijudicial e a arbitral.

A perícia judicial é aquela que envolve o poder judiciário, ocorrendo no seu âmbito. As partes litigantes podem solicitar a realização de perícia, neste caso ela será requerida. $\mathrm{O}$ magistrado também poderá determinar a realização dessa prova, face à necessidade de um laudo técnico-científico, neste caso a perícia é determinada de ofício (MORAIS, 2000). É específica e define-se pelo texto da lei, estabelecido no art. 420 do CPC: "A prova pericial consiste em exame, vistoria ou avaliação". O exame envolve a inspeção de fatos, pessoas ou coisas; a vistoria é a constatação (documental ou factual) do estado ou situação da coisa; e a avaliação tem, geralmente, por objetivo, atribuir valores a coisas.

Entende-se por perícia extrajudicial a que ocorre fora do âmbito do poder judiciário. Geralmente ocorre na realização de reavaliações patrimoniais, fusões, cisões, mas também pode ocorrer como forma amigável de solucionar um litígio. Nesse último caso o perito teria que ser de confiança de ambas as partes. Tem uma grande peculiaridade, o fato de poder ser exercido por pessoa jurídica, além de não existir, em via de regra, a figura do perito-contador assistente, conforme é verificado nos termos da Lei $6.404 / 76$ em seu art. $8^{\circ}$ e no Decreto 3.000/99, que dispõe sobre o Regulamento do Imposto de Renda.

A arbitragem no Brasil é uma forma de justiça privada recente, criada pela Lei 9.307 de 23 de setembro de 1996, com o objetivo de resolver conflitos oriundos de bens patrimoniais disponíveis, garantindo às partes a livre escolha de um "árbitro" que será denominado de "juiz arbitral" para o julgamento do objeto da lide. De acordo com Hoog e Petrenco (2002) neste tipo de perícia admite-se que o árbitro seja também o perito da causa simultaneamente.

A perícia semijudicial ocorrerá nos casos onde a perícia ocorre dentro do aparato do Estado, porém fora da esfera judicial, para auxliar na decisão de autoridades parlamentares, policiais e administrativas. (ALBERTO, 1996). O perito seguirá normas emanadas pela organização estatal onde realizará a perícia. Podemos citar como organizações estatais os tribunais de conta dos estados e municípios, conselhos de recursos fiscais e comissões parlamentares de inquérito.

\section{Laudo pericial}

O laudo pericial consiste no resultado da perícia judicial, conforme se observa do art. 433 do CPC. De acordo com Lopes de Sá (2002) trata-se de "uma peça tecnológica" mediante a qual o perito contador se pronuncia a respeito das questões que lhe são formuladas. Por meio dela, o perito contador expressa, de forma circunstanciada, clara, objetiva, e de fácil compreensão, as sínteses do objeto da perícia, os estudos e as observações, as diligências realizadas, os critérios adotados, os resultados fundamentados e as suas conclusões, e será com base neste laudo que o magistrado poderá decidir o litígio em questão, de forma correta, imparcial e justa.

O laudo deverá conter todo o desenvolvimento da tese levantada pelo profissional, no intuito de convencer a autoridade presidente do processo certeza jurídica quanto à matéria fática. Uma vez identificado o cerne da questão, o perito deve debruçar-se sob o questionamento proposto, visando esclarecê-lo da melhor forma possível. Conclui-se que: fundamentação adequada, embasamento doutrinário consistente, opinião conclusiva e redação clara e objetiva, são elementos essenciais na elaboração da peça.

Segundo Alberto (1996), ao elaborar o laudo pericial é fundamental observar diversos aspectos formais que darão clareza a esta peça de comunicação. No entanto, de acordo com Morais (2000), trata-se de uma "prova de execução da perícia", mas não se constitui garantia 
de que a perícia atingiu seu objetivo. É necessário que tenha sido obtida por meio de pesquisa e investigação dos fatos, atributos fundamentais de sustentação para sentença do Juiz, ainda que não se constitua única fonte de informações.

\begin{abstract}
Após a entrega do laudo pericial, pode haver situações em que seja necessário o perito participar das audiências, para esclarecer alguma dúvida que por ventura venha a surgir por parte do magistrado ou pelas partes envolvidas no processo. Durante as audiências, o perito será argüido pelo juiz, e caso as partes desejem algum esclarecimento, poderão pedi-lo através do juiz (MAGALHÃES et al, 1998).
\end{abstract}

\title{
Parecer pericial contábil
}

O parecer pericial contábil é importante instrumento de subsidio, pelo qual o Perito Contador assistente emite opinião sobre as diligências realizadas, disponibilizando ao juiz e às partes, significativos resultados para dirimir o litígio. Sua finalidade é dar opinião fundamentada sobre o laudo, sua preparação é exclusiva do perito-contador assistente, a respeito da sua concordância ou não com o laudo pericial contábil. Magalhães et al. (1998) afirmam que o perito contábil, ao atuar na função de assistente técnico, pode oferecer colaboração aos advogados, debatendo com os mesmos as possibilidades técnicas quanto ao desenvolvimento da prova técnica contábil, sugerindo quesitos ou proposições que possam solucionar os fatos controvertidos objeto da lide.

Para Morais (2000) "O parecer do perito assistente, poderá ter as mesmas características do laudo pericial, pois se trata de um laudo técnico, embora chamado de parecer".

Segundo Jesus (2000), "serve para subsidiar as partes, bem como para analisar de forma técnica e cientifica o laudo pericial contábil".

\section{METODOLOGIA}

A pesquisa é considerada exploratória-descritiva por ter como objetivo principal explorar um determinado fenômeno em tempos e locais definidos, descrevendo as suas características a partir dos dados coletados. Andrade (1997) diz que é através da pesquisa exploratória que se pode avaliar a possibilidade do desenvolvimento de um bom trabalho científico e de se estabelecer os critérios a serem usados e os métodos e técnicas que poderão ser utilizados. Esta mesma autora fala que na pesquisa descritiva "os fatos são observados, registrados, analisados, classificados e interpretados, sem que o pesquisador interfira sobre eles. Portanto, os fenômenos são estudados, mas não manipulados pelo pesquisador" (Andrade, 1997, p.15).

A Justiça Estadual do Estado de Alagoas foi a instituição onde a pesquisa se desenvolveu. Todavia, o universo da pesquisa foi limitado ao Fórum Jairon Maia Fernandes, na Comarca de Maceió, e às 13 (treze) Varas Cíveis Estaduais. Os atores entrevistadas foram chamadas de usuários, afinal o primeiro requisito para que um magistrado fizesse parte da amostra entrevistada era o de ser um usuário efetivo da Perícia Contábil.

Para o propósito do presente estudo, visando uma maior confiabilidade, a amostra foi formada por Juízes que fossem titulares de Varas Cíveis, pois sabe-se que as Varas que mais utilizam a prova pericial contábil, são as cíveis, além do que a nomeação do perito é de estrita responsabilidade do magistrado. A entrevista foi feita por meio de questionário estruturado, baseando-se na literatura que norteia a pesquisa em tela; além de observações dos próprios pesquisadores. O tratamento dos dados deu-se através da estatística descritiva.

O estudo se limitou a uma única esfera judiciária, a Justiça Estadual de Alagoas Comarca de Maceió, sendo assim, um estudo de um único caso. Buscou Analisar a utilização dos laudos periciais contábeis em função de possuírem linguagem simples, clara, concisa e objetiva, na visão dos magistrados. Nenhum outro tipo de perícia, que não fosse a contábil, foi 
alvo da pesquisa. O conjunto de atores entrevistados foi composto apenas por magistrados das 13 (treze) Varas Cíveis da Justiça Estadual de Alagoas, Comarca de Maceió. Dessa forma, todas as conclusões encontradas são exclusivas da entidade estudada, não podendo ser generalizadas para outras organizações.

\title{
4 ANÁLISE DOS RESULTADOS
}

Após o recebimento de nove questionários, de um universo de treze, que foram enviados para as varas cíveis estaduais da comarca de Maceió, procedeu-se à tabulação dos resultados obtidos. Os dados foram tratados, sintetizados e analisados através do uso do Microsoft Excel 2007, buscando responder ao objetivo da pesquisa.

Ao questionar os juízes se os laudos periciais contábeis que vêm sendo produzidos têm conseguido esclarecer os fatos controvertidos que ensejaram o pedido da prova, constatou-se que os trabalhos dos perito-contadores têm sido satisfatoriamente esclarecedores dos objetos da perícia. Esse fato pode ser constatado no Gráfico 1:

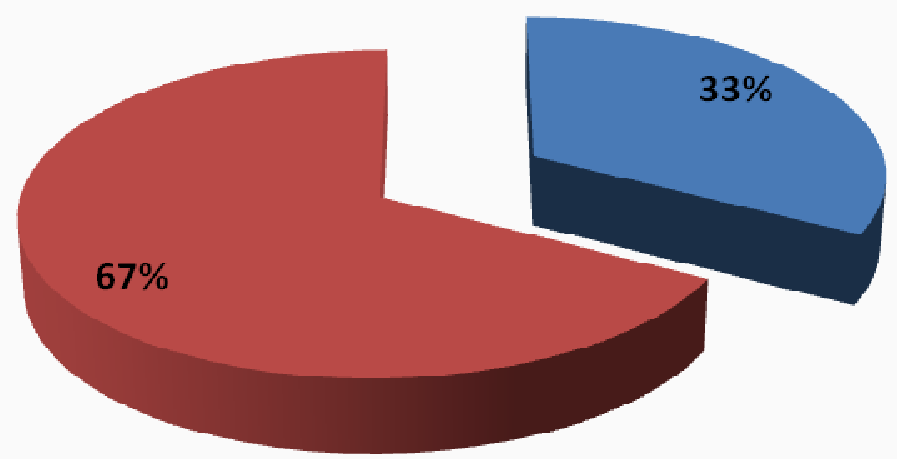

\author{
Concordo Totalmente \\ - Concordo Parcialmente \\ Indiferente \\ - Discordo Parcialmente \\ Discordo Totalmente
}

Gráfico 01 - Fatos Controvertidos

De um modo em geral os magistrados ainda consideram ser necessárias a utilização de uma linguagem mais clara pelos perito-contadores. Em apenas $11 \%$ das observações se identificou que os laudos estão sendo redigidos em uma linguagem clara e simples.

Padoveze (2004) afirma que a contabilidade deve respeitar a necessidade e a forma do usuário utilizá-la. O contador deve sempre estar sempre atento para que a informação contábil seja clara, simples, concisa e objetiva de modo que seu usuário atinja os objetivos que ensejaram sua utilização.
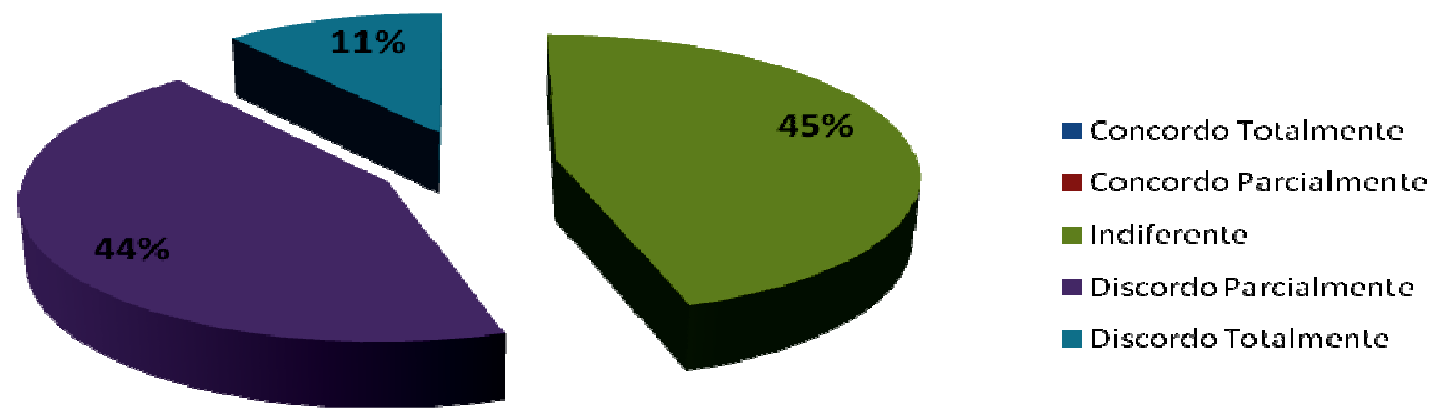

Gráfico 2 - Utilização de Palavras de Sentido Dúbio ou Impreciso

Das nove observações, em nenhum caso foi averiguada uma discordância total com a redação do laudo. Na verdade em quase $70 \%$ dos casos os juízes disseram considerar que a 
prova pericial contábil tem sido bem redigida, necessitando-se apenas de maior atenção gramatical.

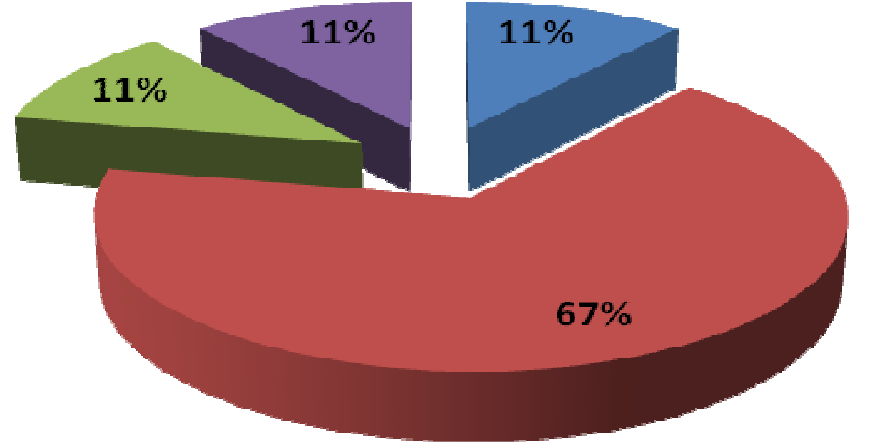

\author{
Concordo Totalmente \\ - Concoredo Parcialmenter \\ Indiferentc \\ - Discordo Parcial rnente \\ Discordo Tolalmente
}

Gráfico 3 - Leitura Fácil

De acordo com a opinião dos juízes, um importante fator para que o perito seja novamente nomeado para realizar algum trabalho, é a aparência e organização da prova pericial acostada aos autos. Dentro da amostra estudada, identificou-se que cerca $80 \%$ dos atores da pesquisa disseram que os trabalhos periciais contábeis têm sido apresentados com uma boa estética.

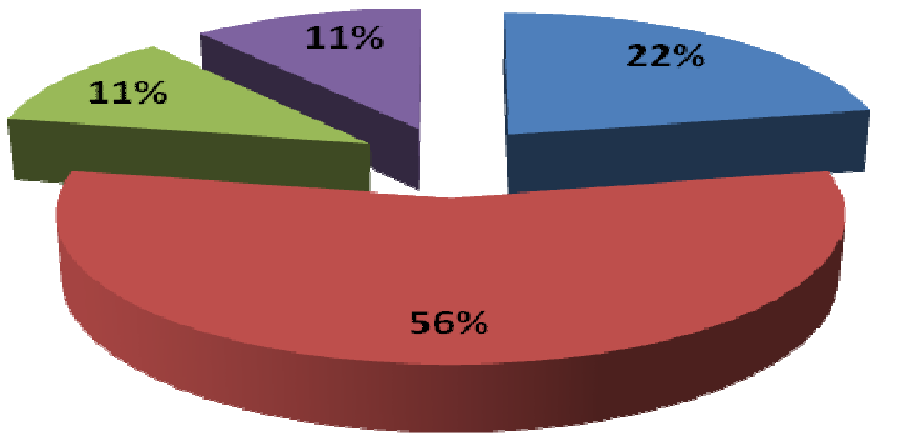

$$
\begin{aligned}
& \text { - Concordo Tolalmente } \\
& \text { Concordo Parcialmente } \\
& \text { Indiferente } \\
& \text { Discordo Parcialmente } \\
& \text { Discordo Totalmente }
\end{aligned}
$$

Gráfico 4 - Estética do Laudo Pericial

Considerando-se que o juiz não tem conhecimento técnico e científico necessário para interpretar as informações que serão acostadas aos autos, foi questionado se eles têm alguma dificuldade pela utilização excessiva de termos técnicos no laudo pericial contábil. Pode ser dito que não há uma resposta unânime sobre a matéria, conforme pode ser verificado no Gráfico 5:

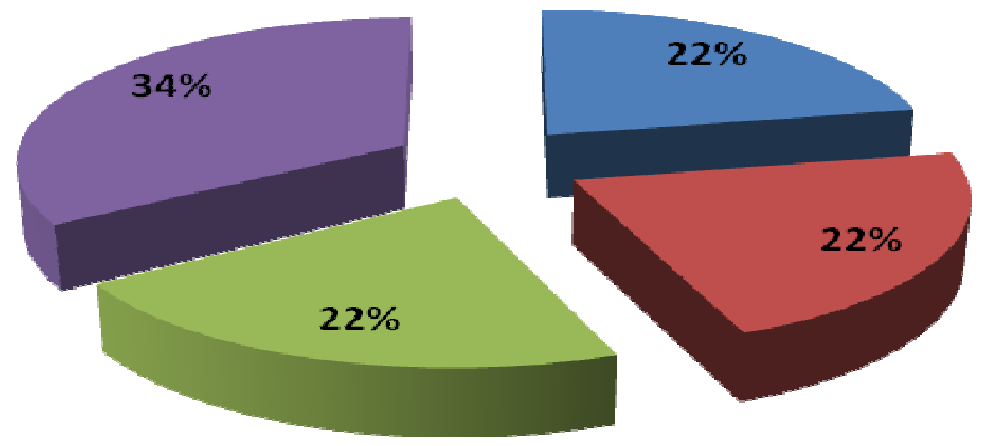

$$
\begin{aligned}
& \text { - Concordo Totalmente } \\
& \text { Concordo Parcialmente } \\
& \text { Indiferente } \\
& \text { Discordo Parcialmente } \\
& \text { Discordo Totalmente }
\end{aligned}
$$

Gráfico 5 - Termos Técnicos 
O trabalho pericial tem como principais norteadores o objeto da perícia e os quesitos elaborados pela parte e pelo juízo. Para pleno atendimento desses o perito deve analisar as peças relevantes que são determinantes para a elaboração do laudo, bem como para a fundamentação da decisão do juiz. Ao se questionar sobre a evidenciação dessas peças nos autos, constatou-se um ponto sensível dos trabalhos entregues aos juízes, por ver que mais de $20 \%$ desses acreditam que tais peças não são salientadas.

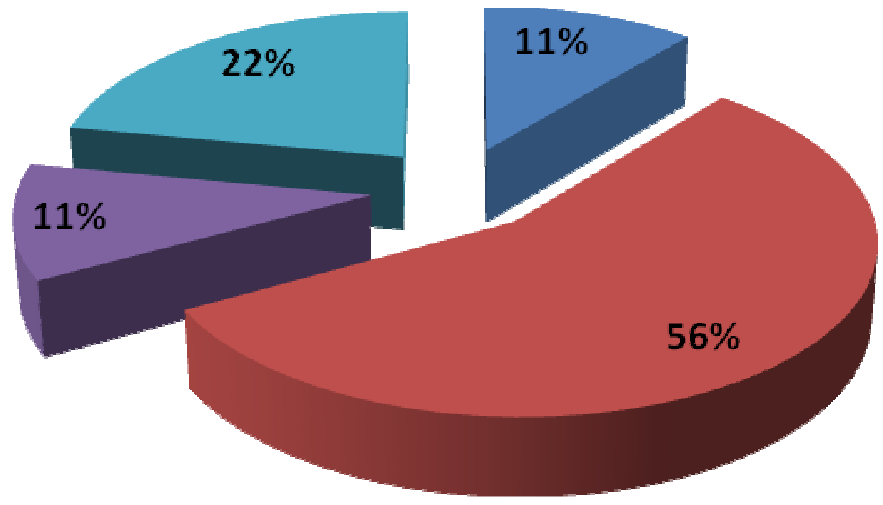

Concordo Totalmente

Concordo Parcialmente

Indiferente

Discordo Parcialmente

Discordo Totalmente

Gráfico 6 - Análise das Peças Relevantes

O Conselho Federal de Contabilidade, através da NBC P 2.9, que trata da educação continuada do perito-contador e do perito-contador assistente, diz que esses profissionais devem comprovar sua educação continuada junto ao órgão de classe, em forma a ser regulamentada. Com base nessa norma, foi questionado aos juízes como eles consideram o fato dos peritos comprovarem junto ao juízo o fato de serem pós-graduados ou não. Notou-se que em cerca $90 \%$ dos casos observados, para nomeação do perito, é levado em consideração o fato do mesmo ser pós-graduado.

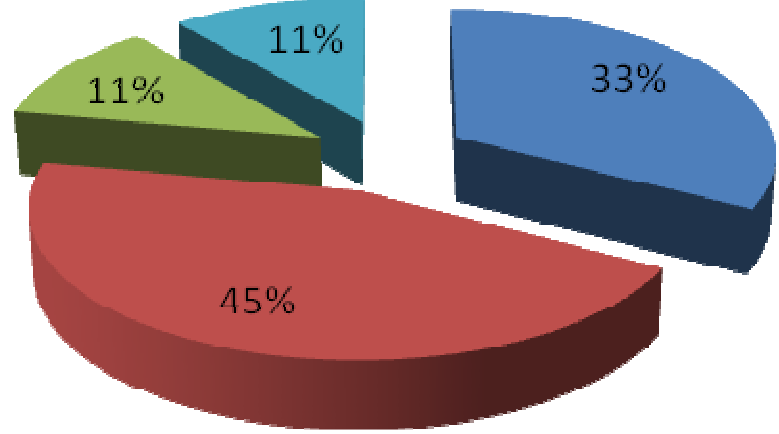

Concordo Totalmente

Concordo parclalmente

Indiferente

Discordo Parcialmente

Discordo Totalmente

Gráfico 7 - O Fato de Ser Pós-Graduado

Para muitos profissionais, um dos principais fatores motivadores, para a elaboração de um trabalho de alto nível é a remuneração que será recebida pelo desenvolvimento dessa tarefa. No caso do perito-contador, na esfera judicial, representado pelos seus honorários. Ao mensurar seus honorários, o perito analisará, tempo, vulto, material humano e físico necessários, e suas responsabilidades para desenvolver o honroso trabalho, para o qual foi nomeado. Na pesquisa efetuada observa-se que, de um modo geral, todos os juízes permitem que os peritos indiquem seus honorários. 


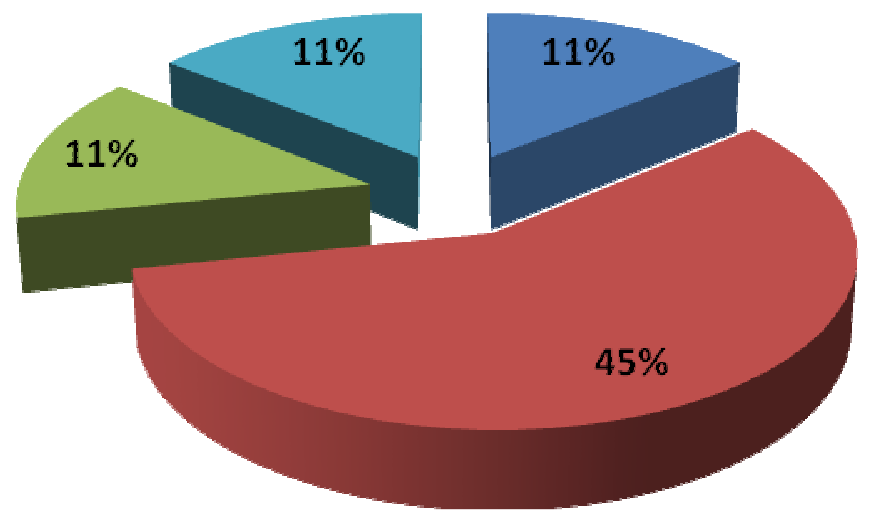

- Concordo Totalmente

- Concordo Parcialmente

Indiferente

- Discordo Parcialmente

Discordo Tolalmente

Gráfico 8 - Indicação dos Honorários

Concluindo o questionário buscou-se verificar quais as principais causas onde são deferidas perícias contábeis. Verificou-se que na justiça estadual de Alagoas, em $89 \%$ das varas participantes da pesquisa, o principal tipo de causa onde é realizada perícia contábil, são as causas de revisões contratuais bancárias.

\begin{tabular}{|l|c|}
\hline \multicolumn{1}{|c|}{ TIPOS DE CAUSAS } & PERCENTUAL DAS VARAS \\
\hline Ações de Indenização & $11 \%$ \\
\hline Medidas Cautelares & $11 \%$ \\
\hline Revisão de Contratos Bancários & $89 \%$ \\
\hline Prestação de Contas & $11 \%$ \\
\hline Causas Imobiliárias & $11 \%$ \\
\hline Causas Empresariais & $11 \%$ \\
\hline Outras & $5 \%$ \\
\hline
\end{tabular}

Quadro 2 - Tipos de Causas

Através da pesquisa identificou-se também que, diferentemente do que vem sido afirmado dentro da academia, os juízes querem os laudos sejam mais conclusivos. Pode-se entender isso como decorrente de provas periciais cujas leituras não sejam suficientemente claras para o entendimento do juiz acerca da informação contábil e, conseqüentemente, fundamentar sua decisão.

Outra observação feita pelos magistrados é o fato de serem apresentados laudos mais discursivos do que explicativos. Eles sentem uma grande carência da apresentação das fundamentações para todas as informações citadas nas provas periciais; seja através de anexos, citações, exposição de fórmulas, dentre outras.

Nesta amostra não foram observados casos de declaração de impedimento pelos peritos nomeados, nem de dificuldades para realização de diligências.

Percebe-se, através das análises do resultado da pesquisa, bem como das observações feitas no local onde foi realizada, que mesmo a perícia sendo considerada uma prova onerosa e demorada por advogados e juízes, quando utilizada costuma ser a principal base fundamentadora das decisões judiciais.

Dessa forma os juízes têm muito cuidado ao nomear perito que ainda não conhece, pois a petição de prova pericial pode servir como agente protelatório para alguma das partes litigantes que não tenha interesse na celeridade da dissolução do litígio. Ocorre que na ocasião de uma primeira nomeação o currículo irá ajudar o perito a ser nomeado, entretanto para que continue trabalhando na esfera judicial, precisa ganhar a confiança dos magistrados, e isso só poderá ser feito através da apresentação de trabalhos que tragam fundamentos claros e convincentes para a decisão judicial. 
A contrapartida oferecida pelos juízes é apenas a de permitir que os peritos indiquem seus honorários, e que caso haja contestação de alguma das partes, ouvir o perito para melhor entendimento dos motivos que o ensejaram a peticionar tal valor.

Também para as partes é importantíssimo que o laudo seja claro, conciso e objetivo, para que possam entender o que o perito entende ser correto acerca do objeto que ensejou a prova pericial contábil. Pode-se dizer, portanto, que há uma importante contribuição do trabalho do perito-contador para a solução de conflitos, tanto para os juízes quanto para as partes envolvidas nos litígios.

\section{CONCLUSÕES}

Este estudo analisou a utilização dos laudos periciais contábeis, observando se possuíam linguagem simples, clara, concisa e objetiva, na visão dos magistrados das varas cíveis estaduais da cidade de Maceió - AL.

No que se refere ao esclarecimento de fatos controvertidos, através da utilização de laudos periciais contábeis, os magistrados afirmaram ser esse um item satisfatório. Entretanto reiteram que os trabalhos periciais desenvolvidos pelos profissionais contadores ainda carecem de melhor fundamentação além de serem mais conclusivos.

Considerando que a contabilidade é uma ciência, em sua essência, de caráter controladora e informativa (PADOVEZE, 2004), os contadores devem estar atentos às necessidades e limitações dos usuários da informação contábil. Todo dado, relatório ou informação emitido deve ter sentido claro, sem deixar dúvidas sobre o que está sendo apresentado. Porém, na visão dos magistrados (principais usuários da perícia contábil na esfera judicial), ainda são utilizadas muitas palavras de sentido dúbio ou impreciso.

A redação da peça probante é determinante para o deslinde dos fatos corridos, e conseqüente fundamentação da decisão judicial. No que tange a esse assunto, foi identificado que os perito-contadores têm tido zelo na elaboração descritiva do laudo pericial.

Juntamente com a boa redação, é imprescindível uma boa apresentação do trabalho. Não apenas no que tange à estruturação do laudo, que é especificada na NBC T 13.6 (editada pelo CFC), mas também se faz necessário que haja cuidado no manuseio do mesmo, para que seja juntado aos autos com boa aparência.

A mesma norma citada imediatamente acima, reza que a linguagem adotada pelo perito-contador deve permitir ao julgador e às partes litigantes, conhecimento e interpretação dos resultados dos trabalhos periciais contábeis. Na amostra analisada, esse é um fato controvertido, haja vista que os juízes consideraram que há um excesso de utilização de termos técnicos, e em outras existe uma visão oposta à primeira.

De um modo geral os magistrados destacam ainda a importância de dar-se maior evidenciação das peças que são relevantes para fundamentar as conclusões do trabalho pericial, bem como as decisões judiciais. Todos os atores da amostra dizem considerar importante o fato do perito ser pós-graduado.

Entretanto esse não é motivo principal, muito menos único, para a nomeação do perito. O perito é um profissional de confiança do juiz, logo a qualidade de seus trabalhos é quem garantirá a continuidade de seus serviços no juízo.

Seguindo o rito ordinário comum, que foi comentado no capítulo dois, na esfera da justiça estadual em Alagoas, os magistrados costumam, via de regra, solicitar que os peritos indiquem seus honorários. Possibilitando assim, que os mesmos apresentem seus planejamentos e expectativas.

Finalmente, a análise demonstra que as revisões contratuais bancárias são os principais tipos de causas para as quais designam perícia contábil. Os profissionais de contabilidade que militam no campo da perícia contábil judicial além de possuir o

R. Cont. Ufba, Salvador-Ba, v. 4, n. 1, p. 23-35, janeiro-abril 2010 
conhecimento e prática das normas legais referentes à prova pericial, estar devidamente registrados no conselho de classe, seguir os preceitos éticos sociais e os regulados pelo código de ética do profissional contábil, devem estar atentos às expectativas dos juízes para que, dessa forma, possam atender plenamente ao serviço para o qual foram nomeados.

Ao iniciar o trabalho pericial, o perito deve averiguar quais são - exatamente - os fatos controvertidos, além dos motivos que os geraram. Essas observações precisam ser destacadas antes das conclusões do laudo pericial, para que toda a informação prestada seja organizada de forma lógica, facilitando assim o entendimento do que realmente ocorreu, logo, permitindo ao juiz tomar uma decisão correta.

Dentro de um processo são produzidas provas e levantados fatos antes do início da prova pericial. Para elaboração do laudo pericial contábil, o contador deve evidenciar quais dessas peças são realmente relevantes, ou seja, quais realmente têm valor como fundamentação na criação da prova, bem como para decisão do magistrado. Há de se ter atenção à apresentação do laudo também. A organização estética do laudo, bem como de qualquer texto, facilita a percepção dos fatos expostos fazendo com que a leitura da prova pericial seja mais fácil. Entretanto, apenas uma boa estética não é suficiente, o perito tem que estar atento à redação do texto. A utilização de termos técnicos em excesso, bem como de palavras com sentido dúbio ou impreciso prejudicará a decisão judicial. O perito deve servir como agente facilitador dentro do processo, não apenas produzindo a prova, mas realizando essa tarefa de modo que os usuários da informação gerada possam entender claramente o que a foi concluído através da elaboração da prova. Toda informação deve ser clara, concisa, simples e objetiva.

A função de perito judicial é de extrema confiança do juiz, ou seja, o magistrado sempre estará nomeando profissionais nos quais tenha insuspeição. Nessa pesquisa foi identificado que os magistrados das varas cíveis estaduais de Alagoas, na comarca de Maceió, também consideram importante o fato do perito-contador manter constante atualização profissional, através de cursos de pós-graduação. Esse é um fator relevante na indicação dos honorários periciais, pois quanto maior for a qualificação do profissional maior será a mensuração de suas horas trabalhadas. Além disso, o perito-contador deve estar atento aos tipos mais comuns de causas para que possa, antecipadamente, estudar e se preparar para algum trabalho pericial para o qual possa vir a ser nomeado.

\section{REFERÊNCIAS}

ALBERTO, Valder Luiz Palombo. Perícia Contábil. São Paulo: Atlas 1996.

ANDRADE, Maria Margarida. Como preparar trabalhos para cursos de pós-graduação. 2ed. São Paulo: Atlas, 1997.

ANJOS, Luiz C. M; LIMA, Márcia M. S; MARTINS, Joana D’Arc M. O papel do perito contador na solução de litígios judiciais: um estudo de caso nas varas cíveis de Maceió/AL. V Simpósio de Gestão e Negócios, Seropédica, 2007. Anais... Rio de Janeiro, UFRRJ, 2007.

BRASIL. Lei 5.869 de 11 de janeiro de 1973 - Código de Processo Civil (CPC). Disponível em: http://www.planalto.gov.br Acesso em: 20 de fevereiro de 2009.

CABRAL, Alberto Franqueira. Manual da prova pericial. Rio de Janeiro: Impetus, 2003.

CONSELHO FEDERAL DE CONTABILIDADE. Normas Brasileiras de Contabilidade Técnica 13: Perícia Contábil. Disponível em: http://www.cfc.org.br Acesso em: 15 de fevereiro de 2009. 
Normas Brasileiras de Contabilidade - Profissional 2: do Perito Contábil. Disponível em: http://www.cfc.org.br Acesso em: 15 de fevereiro de 2009.

FONSECA, Alice Aparecida da Silva et al. Revista Brasileira de Contabilidade. Ano XXIX n ${ }^{\circ}$ 123. Brasília. Mai/Jun 2000.

HOOG, Wilson A. Z. e PETRENCO, Solange Aparecida. Aspectos práticos e fundamentais da prova pericial contábil. 2 ed. Curitiba: Juruá, 2002.

JESUS, Fernando. Perícia e investigação de fraude. Goiânia: Editora Terra, 2000.

LOPES DE SÁ, Antônio. Perícia Contábil. 5 ed. São Paulo: Atlas, 2002.

MAGALHÃES, Antônio de Deus Farias et al. Perícia contábil: uma abordagem teórica, ética, legal, processual e operacional. São Paulo: Atlas, 1998.

MORAIS, Antônio Carlos et al. Perícia judicial e extrajudicial. Brasília: Editora Qualidade, 2000.

OLIVEIRA, Celso M. Responsabilidade civil e penal do perito: o profissional de contabilidade na nova legislação civil e falimentar. Disponível em: $<$ http://jus2.uol.com.br/doutrina/texto.asp?id=6520>. Acesso em: 10 de setembro de 2007.

ORNELAS, Martinho M. Perícia Contábil. 3ed. São Paulo: Atlas,2000.

PADOVEZE, Clóvis L. Sistemas de informações contábeis: fundamentos e análise. 4 ed. São Paulo:Atlas, 2004. 